MATEC Web of Conferences 26,01001 (2015)

DOI: $10.1051 /$ matecconf/ 20152601001

(C) Owned by the authors, published by EDP Sciences, 2015

\title{
The Effect of Different Sintering Strategies on Properties of YSZ Reinforced Graphene Composites
}

\author{
Kalaimani Markandan ${ }^{\mathrm{a}}$, Jit Kai Chin ${ }^{\mathrm{b}^{*}}$ and Michelle T.T Tan ${ }^{\mathrm{c}}$ \\ Division of Materials, Mechanics and Structures, Center of Nanotechnology and Advanced Materials, Faculty of Engineering, University of \\ Nottingham Malaysia Campus, Jalan Broga, 43500, Semenyih, Selangor, Malaysia
}

\begin{abstract}
Partial, single and double step sintering has been carried out to densify YSZ reinforced $1 \mathrm{wt}$ \% graphene composites at temperature as low as $40 \%$ of the homologous temperature. The influence of sintering conditions on resulting density, microstructure, porosity and contact angles were determined. The microstructure of the composites showed that amount of micro pores was reduced upon double step sintering and infiltrating with PDC resin. This study has improved upon existing sintering methods resulting in the use of low temperature for sintering ceramics yet achieving relative density $>95 \%$ with porosity as low as 0.15 using double step sintering.
\end{abstract}

\section{Introduction}

Sintering is a complicated microstructure evolution process; wherein the major aim is porosity elimination[1-3]. As such, the major aim of this study is to shed light and investigate the influence of various sintering strategies (partial step sintering, single step sintering and double step sintering) on the porosity elimination of ceramics. Hence, main attention is addressed in the relative density, grain size, pore size and percentage porosity of YSZ reinforced graphenecomposite which are ideally well suited for manufacturing of engineering components subjected to large mechanical stresses and extreme conditions such as hostile environments and high temperatures [4]. Besides, temporal variations on the surface energy of the ceramic were studied using a goniometer.

\section{Experimental procedures}

\subsection{Preparation of Ceramic Suspension}

The procedure for preparation of YSZ reinforced graphene suspension has been reported previously [5]. In short, Yttria Stabilised Zirconia (YSZ) reinforced with 1 wt. \% graphene was used as the structural material; where the green bodies were obtained by gelcasting on PDMS soft molds.

\subsection{Sintering Mechanism}

Different strategies were implemented to densify the composite of the green body; (a) single step sintering at temperature of $1200^{\circ} \mathrm{C}$ for 4 hours; (b) double step sintering by ramping the temperature to $1200^{\circ} \mathrm{C}$, reduced immediately to $900^{\circ} \mathrm{C}$ and held for 30 hours (c) partial sintering at lower temperature of $900^{\circ} \mathrm{C}$ for 2 hours. After natural cooling to room temperature, the ceramics were removed and immersed into a polymer derived ceramic (PDC) resin (RD-212a, Starfire Systems Inc.) for an hour followed by thermal curing of the resin at $250^{\circ} \mathrm{C}$ for an hour. The ceramics were reheated for 2 hours at $900^{\circ} \mathrm{C}$ for conversion of the resin into SiOC ceramic.

\subsection{Characterizations}

The bulk density of all samples was determined via Archimedes method using a pycnometer (Laborglass,Germany). Porosity of the ceramics were determined using Eq. 1;

$$
\text { Porosity }=\left[1-\left(\frac{\rho_{\text {bulk }}}{\rho_{\text {theoretical }}}\right)\right] \times 100 \%
$$

Where $\rho_{\text {bulk }}$ is the bulk density of the ceramic composite $(\mathrm{g} / \mathrm{cm} 3)$ and $\rho_{\text {theoretical }}$ is the theoretical density of the ceramic composites $(\mathrm{g} / \mathrm{cm} 3)$.A contact angle goniometer (Model 250, Rame-Hart) was used to measure the contact angle between the liquid droplets and sintered YSZ-graphene surface. Microstructures of YSZ-graphene composites fabricated via different sintering mechanisms were investigated using highresolution SEM (SEM, Quanta400F, FEI).

\section{Results and discussion}

The effect of different sintering strategies on the relative density, grain size, pore size and porosity are as

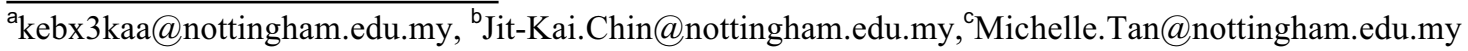


depicted Figure 1. It indicates that porosity decreases as relative density increases and pore size decreases as grain size increases. Furthermore, porosity variation is due to YSZ grain size upon various sintering mechanisms. The porosity after double step sintering was reduced for YSZ particles in comparison to that of single step sintering or partially sintering. This phenomenon is due to improved compressibility of particles upon double step sintering, leading to grain growth. Higher relative density was achieved at higher temperature; partial step sintering at $900^{\circ} \mathrm{C}$ (rel. density
$93 \%$ ), single and double step sintering at $1200^{\circ} \mathrm{C}$ (rel. density 94.1 and $95.4 \%$ respectively).As shown in Eq. (2), the rate of diffusion depends on the sintering temperature. As such, denser structure is achieved at higher sintering temperature.

$D=D_{O} \exp \left(\frac{-Q}{R T}\right)$

Where D is the diffusion coefficient, D0 is the constant, $\mathrm{Q}$ is the activation energy, $\mathrm{R}$ is Boltzmann constant and $\mathrm{T}$ is the temperature.

Table 1. Properties of composite after various sintering

\begin{tabular}{ccccc}
\hline Processing & $\begin{array}{c}\text { Relative } \\
\text { density }(\%)\end{array}$ & $\begin{array}{c}\text { Grain size } \\
(\mathrm{nm})\end{array}$ & $\begin{array}{c}\text { Average pore } \\
\text { size }(\mathrm{nm})\end{array}$ & $\begin{array}{c}\text { Porosity } \\
(\%)\end{array}$ \\
\hline Partial & 93 & $167 \pm 18$ & $126 \pm 13$ & 23.3 \\
\hline Single & 94.1 & $186 \pm 21$ & $98 \pm 16$ & 16.7 \\
\hline Double & 95.4 & $194 \pm 16$ & $76 \pm 17$ & 15.1 \\
\hline
\end{tabular}
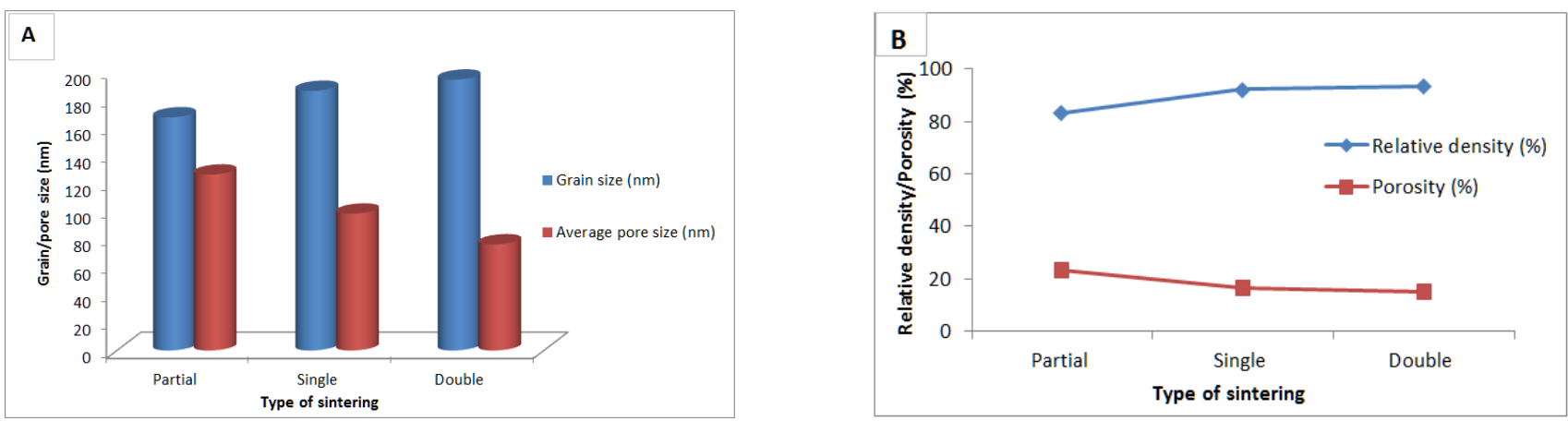

Figure 1. Effect of various sintering on (a) relative density and porosity of ceramic (b) grain and pore size.

Besides, it should be noted that sintering time of double step sintering was relatively high (30 hours) in comparison to single step sintering (4 hours) and partial step sintering ( 2 hours).The evolution of microstructure with sintering time is as depicted in Figure 2. The dependence of the diffusion to time can be explained by Eq. (3),

$$
r=2.4 \sqrt{D t}
$$

Where $r$ is radical distance, $D$ is the diffusion coefficient and $t$ is the sintering time. It can be seen that atomic displacement is proportional to the square root of time. This is responsible for atomic diffusion which leads to grain coarsening. Thus, the manifestation of Eq. (3) can be clearly seen by the changes in morphology and the size of pores and grains.
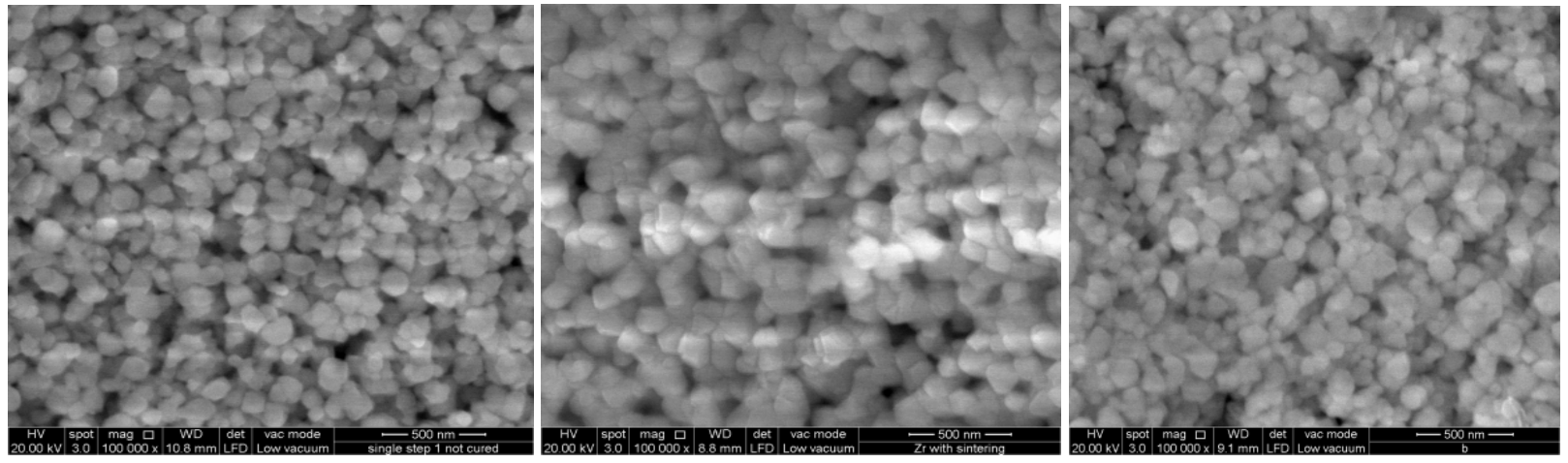

Figure 2. SEM images of YSZ reinforced with $1 \mathrm{wt} \%$ graphene after (a) partial step sintering (b) single step sintering (c) double step sintering 
Contact angle measurements on composites were used in an effort to determine the surface energies. Surface energies are important to understand the wetting and adhesion properties of materials. However, determining surface energy is not trivial whereas measuring contact angle is simpler. In this study, the contact angles of deionized water droplet on the ceramic surface are plotted against time for gradual decrement of angles as the liquid penetrates through the surface of the composite (Figure 3). It is observed that the composite fabricated via double step sintering has higher contact angle $\left(>90^{\circ}\right)$ in comparison to those via single step and partial step sintering respectively. This is attributed by the presence of lesser pores (quantity and size) that leads to contact angles greater than $90^{\circ}$; designated as hydrophobic surfaces.

Figure 4 shows the effect of different types of sintering on volume reduction of water droplet on ceramics. It is evident that the volume decreases more slowly with double step sintering compared to that of partial step sintering and single step sintering; partially sintered composites has a steeper slope in comparison to single step sintered and double step sintered composites.

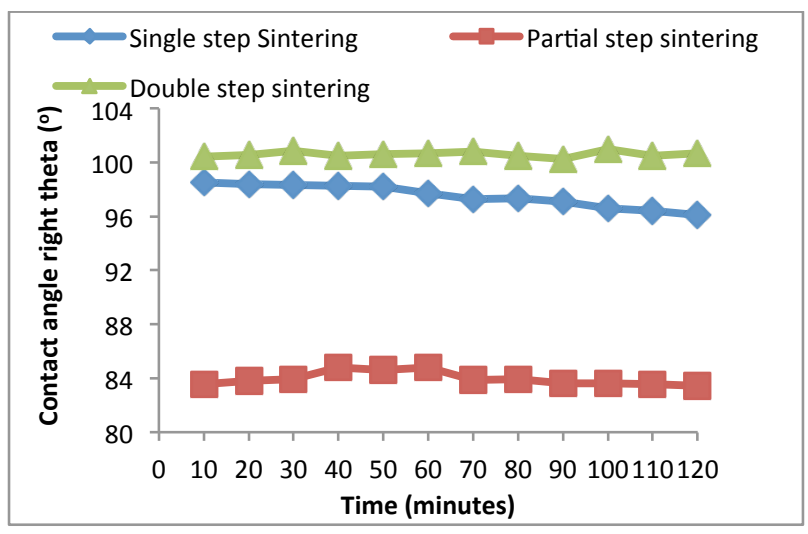

Figure 3. Effect of sintering on right theta

$m_{\text {partial step sintering }}>m_{\text {single step sintering }}>m_{\text {double step sintering }}$
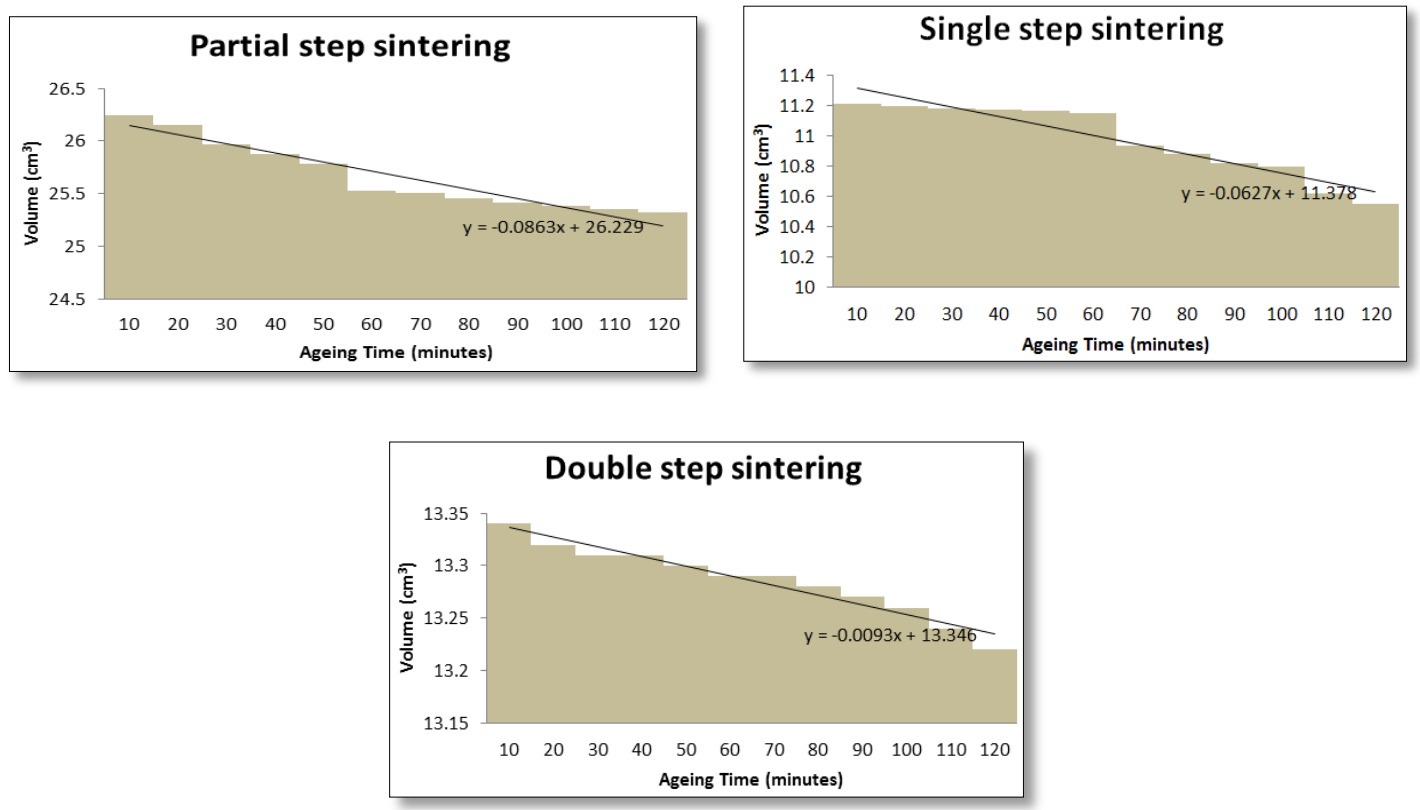

Figure 4. Effect of various sintering mechanism on volume reduction on ceramic surface.

\section{Conclusion}

The influence of different sintering mechanisms on the microstructure, density, porosity and contact angles was investigated. Experimental findings establish double step sintering as an effective sintering mechanism at low temperature yet achieving relative density $>95 \%$ and low porosity $(0.15)$ in comparison to partial or single step sintering.

\section{Acknowledgement}

The authors would like to acknowledge the financial support from the Ministry of Science, Technology and Innovation of Malaysia for the research grant (EScience code: 04-02-12-SF0198).

\section{References}

1. Rahimian M, Ehsani N, Parvin N, Baharvandi HR. The effect of particle size, sintering temperature and sintering time on the properties of $\mathrm{Al}-\mathrm{Al} 2 \mathrm{O} 3$ composites, made by powder metallurgy. J Mater Process Technol., 209[14] (2009) 5387-93. 
2. Wang C-J, Huang C-Y, Wu Y-C. Two-step sintering of fine alumina-zirconia ceramics, Ceram Int., 35[4] (2009) 1467-72.

3. Yadhukulakrishnan GB, Karumuri S, Rahman A, Singh RP, KaanKalkan a., Harimkar SP. Spark plasma sintering of graphene reinforced zirconium diboride ultra-high temperature ceramic composites. Ceram Int. 39[6] (2013):6637-46.

4. Román-Manso B, Sánchez-González E, Ortiz AL, Belmonte M, Isabel Osendi M, Miranzo P. Contact- mechanical properties at pre-creep temperatures of fine-grained graphene/SiC composites prepared in situ by spark-plasma sintering. J Eur Ceram Soc. 34[5] (2014):1433-8.

5. Markandan K, Tan MT., Chin J, Siew Shee L. A novel synthesis route and mechanical properties of Si-O-C cured yytria Stabilised zirconia (YSZ)graphene composite. Ceram Int. 41[3] (2015): $3518-3525$. 